\title{
Operator-Oriented Product and Production Process Design for Manufacturing, Maintenance and Upgrading
}

\author{
Gu van Rhijn and Tim Bosch
}

\begin{abstract}
The nature of production in the manufacturing industry is changing, and companies face large challenges. Customers expect fast delivery times, proven sustainability, flexibility, and frequent product upgrades. To stay competitive and manage rapid technological demands, a parallel, iterative and interactive development approach for product and process design is required. Closed-loop systems will increase future customer demand for easy upgrading. This requires highly modular and operator-friendly product designs. Because the complexity, variety and unpredictability of products and production tasks will increase, information and support systems for operators are crucial elements. Human factor engineering methodologies are essential to take full advantage of new technologies that support operators in all stages of the product life cycle. Methods and tools that could support companies in improving product, process, and workstation design are presented, and directions for future research and tool development are discussed.
\end{abstract}

Keywords Production process design - Modular product design - Task allocation · Human factors - Operator support

\section{Introduction}

\subsection{Industrial Challenges: Changing Market Demands}

The nature of production in the manufacturing industry is changing, and companies face large challenges (Fig. 1). Market demands are less predictable, and the time-to-market is shorter. Manufacturers of components, modules and products need to have flexible and efficient production processes to achieve fast delivery of

G. van Rhijn ( $\square) \cdot$ T. Bosch

TNO, PO Box 30052301 DA, Leiden, The Netherlands

e-mail: Gu.vanrhijn@tno.nl

T. Bosch

e-mail: tim.bosch@tno.nl

(C) The Author(s) 2017

S.N. Grösser et al. (eds.), Dynamics of Long-Life Assets,

DOI 10.1007/978-3-319-45438-2_8 

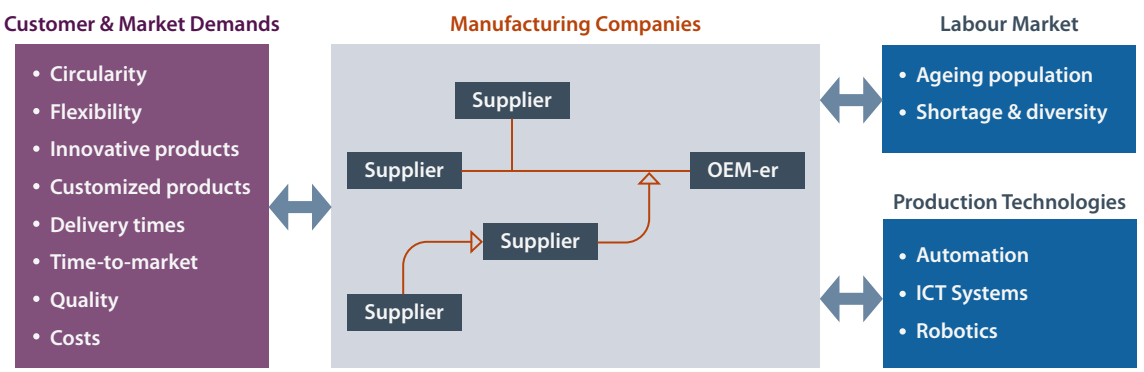

Fig. 1 The nature of production in the manufacturing industry is changing

high quality products within the context of variation in volume demands, a large mix of customer-specific product types, and short product life cycles (Van Rhijn et al. 2005; Aberdeen Group 2014). Costs, efficiency, quality, and innovative designs are still important drivers of manufacturing companies. However, driven by market demands, short product development lead times, proven sustainability, flexibility, and frequent product upgrades will become crucial elements to guarantee competitiveness, especially for manufacturers of high-investment products.

Customers have become more environmentally conscious. The global market for environmentally friendly goods and services was estimated at €4.2 trillion in 2011 (Department for Business, Innovations and Skills 2012). Manufacturers of capital-intensive products must prove the circularity of product designs and manufacturing processes (e.g., end-of-life options, sources of materials, sustainability of suppliers). Currently, most products are designed, produced, and sold to the end-user. In case of malfunction, outdatedness, or the changing requirements of the end-user, a new product is designed, produced, and sold. The circular economy concept aims to keep products, components, and materials at their highest utility and value at all times (e.g., Ellen MacArthur Foundation 2013; McKinsey 2011). In contrast to a traditional linear economy, i.e., 'take-make-dispose', the circular economy emphasizes the reusability of products and raw materials as a starting point and minimizes waste in the entire industrial and ecological system. To take full advantage, it is important for manufacturers to consider that products and components can be given a second or longer life during the design process (e.g., by 'design for disassembly, for maintenance, for reuse or remanufacturing') (Bastein et al. 2013). These challenges are topics in the Use-it-Wisely (UIW) project and objectives: Design of adaptable and upgradable products and flexible (re)manufacturing processes are crucial aspects for realizing a circular economy-based business. Remanufacturing is commonly defined as "a series of manufacturing steps acting on an end-of-life part or product to return it to like-new or better performance, with warranty to match" (APPSRG 2014). 


\subsection{Industrial Challenges: Changing Production Technologies}

Simultaneously, production technology is developing quickly (Fig. 1). The trend of automation, including the use of robots and process control systems, has a large impact on manufacturing. Manufacturing companies $(\mathrm{OEM}=$ Original Equipment Manufacturers and their suppliers) face large challenges from the market, from a technology perspective and from the labour market. 'Full automation' however, is often not feasible in assembly work, specifically in the combination of low volumes, high product mix, and high product complexity. Therefore, hybrid production systems in which humans and robots or robot systems are intuitively collaborating are needed. A recent report on the current state of the Dutch manufacturing industry stated (Smart Industry, Dutch Industry fit for the future 2014): "Humans are still the most flexible production factor. As smaller batches require higher investments and specialised production systems, especially in assembly, robots and robot systems will often mainly assist production personnel and remove some routine work". Finally, the labour market in itself is facing challenges; the proportion of older employees is rising due to the ageing population (Bloom et al. 2015). Skilled, flexible and motivated employees have become crucial 'assets' for companies to handle all those challenges.

The challenges and developments from the market (customers), technology breakthroughs and the labour market are summarized in Fig. 1. How can the manufacturing industry respond to the challenges of changing customer demands and technological developments?

In the UIW-project, tools and methods are developed and demonstrated to support companies in designing both adaptable and upgradable products and flexible (re)manufacturing processes. Closed-loop systems will necessitate the allowance of easy upgrading for future customer demands. This requires highly modular and operator-friendly product designs. To take full advantage of new technologies that support operators in all stages of the product life cycle, human factor engineering methodologies are essential. The starting point is a parallel, iterative and shared development approach for products and flexible (i.e., agile) production processes (Fig. 2). Part of this approach is two essential elements or 'building blocks':

1. A highly modular and operator-friendly product design that allows easy upgrading, remanufacturing and maintenance of new, refurbished and remanufactured products;

2. Flexible, human-centred production processes using new technologies, including workstations with correct levels of automation and assistive technology that support operators.

During the product and process development stage, manufacturing companies must pay attention to these two elements in an interconnected way because they are closely linked and thereby affect each other. Figure 2 shows an overview of the 


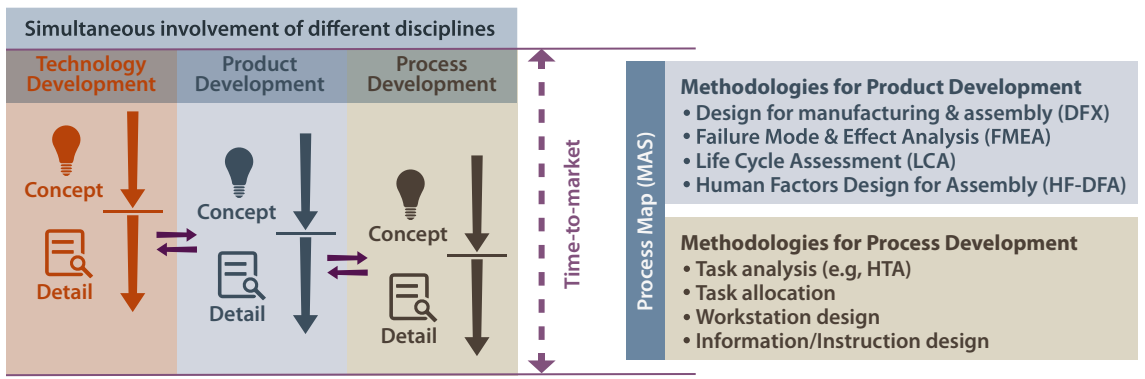

Fig. 2 A parallel, iterative and interactive development approach for modular product and flexible human-centred production processes supported by different methodologies

methodologies available to support parallel and early-stage development of modular products and flexible, human-centred production processes within the scope of high-investment products in the manufacturing industry. In this chapter, we will describe solutions to manage the above-mentioned company challenges and provide more detail about specific methodologies. More specifically, Sect. 2 describes methodologies for parallel and early stage development of products and production processes. Section 3 describes methodologies for (dis)assembly, maintainability, upgrading and modular product design. Sect. 4 presents the application of assistive technologies to support operators in a proper manner.

\section{Methodologies to Support Parallel Product and Process Design}

To support companies in developing new products, (re)manufacturing and upgrading processes, which are sustainable throughout the complete life cycle, several engineering and human factor methodologies are described in the literature. These methodologies may be used during the development of new technologies, products and production processes (see Fig. 2).

Examples of methodologies used during the product design phase are:

- Design for manufacturing and assembly guidelines (DFA or HF-DFA) to create cost-effective and operator assembly-friendly products (e.g., Boothroyd et al. 2001; Village et al. 2014). These methods and guidelines are used in the application developed in "UIW: the Circular Economy Design Framework" (see Bosch, Chapter "Sustainable Furniture That Grows With End-Users" this book).

- Failure Mode and Effect Analysis (FMEA) to detect problems that might arise from malfunctions in a product (Ginn et al. 1998; Stamatis 2003).

- Sustainable design methodologies such as Life Cycle Assessment (LCA, Pajula, Chapter "Managing The Life Cycle to Reduce Environmental Impacts" this book). 
Process development tools and upgrading methodologies include:

- The lean manufacturing philosophy in the pursuit of reducing wasteful activities and improving productivity and profits (Genaidy and Karwowski 2007).

- Lead time reduction by minimization of Manufacturing Critical-path Time in Quick Response Manufacturing (QRM, Suri 1998) and Demand Flow Factory (Pot and Van Rhijn 2012).

- Value Stream Mapping (VSM) or Business Process Modelling (BPM) tools to build a common perspective of a process workflow (e.g., Rother and Shook 2003).

- To allocate tasks at a process or workstation level, task or function allocation methodologies (e.g., Fasth and Stahre 2010; Challenger et al. 2013) are commonly used.

In practice, these methods are mostly used independently by different company disciplines (i.e., departments) for improving product or process design. Development of products and processes in parallel and with strong interaction between different disciplines: sales, product design, process engineering, and operations (operators from manufacturing, assembly, maintenance) is essential for manufacturing but even more for maintenance, upgrading, and remanufacturing processes. Furthermore, parallelizing technology, product and development (as shown in Fig. 2), shortens time-to-market (first time right) and can save a significant amount of money (Quan and Jianmin 2006). To involve different disciplines in the product and process design phase, a participatory approach can be used.

This participatory approach (e.g., Vink et al. 2008; Hirschheim 1989; Muller and Kuhn 1993) is a well-known and successful approach that could lead to quality improvements and a reduction in costs (European Foundation for the Improvement of Living and Working Conditions 1999). It is a design procedure in which the relevant company stakeholders (e.g., management) and the end-users, i.e., the operators in a production process, engineers developing new products or maintenance personnel out in the field, have the opportunity to influence the content of the design target (Bouckenooghe and Devos 2007; Lines 2004). If situations are complex, a stepwise and iterative approach could be adopted so that the anticipated effort and success could be reviewed. This interactive process, which is essential for gaining support and momentum to push innovation forward, improves communication, manages expectations and uses different perspectives and skills in the design process. The involvement of different disciplines and employees enables a potential resource for creativity and innovation (e.g., Shalley et al. 2004). Moreover, the involvement of employees from different disciplines is also essential because of the great deal of knowledge and experience they have about the products, production processes and problems that occur on a day-to-day basis. For instance, some or all of the workers who will work at a forthcoming plant could take part in a number of design sessions during different design stages (van Rhijn et al. 2014). 


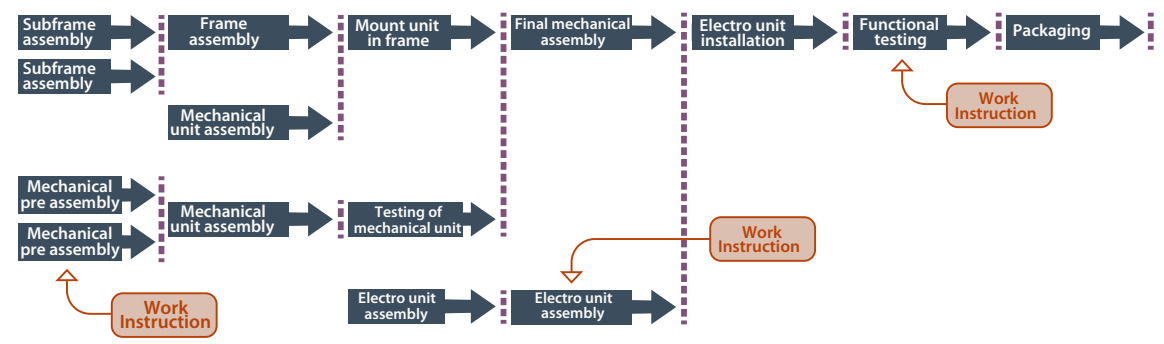

Fig. 3 Schematic representation of the process steps of the (sub) assembly and testing stages with the MAS

A starting point in this (participatory and parallel product and process development) approach is creating a commonly shared process map using the 'MAS' methodology. MAS stands for 'Montage Afloop Schema' (assembly process flow, Van Rhijn et al. 2014). MAS is a graphical representation of successive and parallel process stages, including timing estimates (Fig. 3). This assembly process map can be used to streamline product and process design. It can also be used to compare alternatives to the product structure and the structure of the assembly process in terms of their effects on lead times and productivity both at the concept level and during the detailed development stage.

This focus on process structuring during product design is crucial for delivering components and final products in small series in a short time, as well as for getting it right the first time.

In the product design phase, the MAS instrument is used in the following steps:

- Creating a working group of different disciplines: product designers, engineers, process engineers, and operators from assembly and service/installation. The concept or detailed product design is demonstrated to the working group using drawings, sketches or 3D models. The product structure will be clarified, and a distinction will be made between product modules and individual components.

- The successive and parallel assembly process steps that are needed to assemble the total product from beginning to end are drawn on paper. The starting point is the main process. Every arrow represents a process step, consisting of several (manual) actions/tasks. Just above the arrow, the main process step and the respective part/module is described. Next, to assembly of mounting steps, other essential steps such as handling, turning, rotating or testing the component or modules are described.

- After that, parallel processes in the workflow are listed, which can be assembly or test processes of subassemblies of product modules. These parallel processes are connected to the main process at the stages in which these subassemblies are needed.

- The graphical representation of assembly, testing, packaging activities is then be discussed and adapted by the working group. For instance, the sequence of process steps may be shifted. 
- The time needed for every process step is estimated and added to the process scheme. Based on this, lead times and productivity can be evaluated. Other elements, if relevant, may be added as well. For instance, specific equipment and tools needed or special conditions (cleanroom levels).

- The next step is a review of the product design for modularity and operatorcentred design (see Sect. 3), including modular product structure, exchangeability of modules and parts, reducing the number and variety of parts, simplicity of handling and positioning, and physical load during handling and mounting. Based on this analysis, both the product design and the assembly process scheme may be adapted and improved.

This process work flow method can be used to analyse assembly processes and other primary processes such as maintenance, service, and installation. The advantage of the MAS method is that product and process engineers are forced to think about possible scenarios for the assembly process. Which steps are needed to assemble the product and in which order? Moreover, the modular product structure becomes clear; which units or modules can be distinguished? Modularity results in opportunities for parallel structures that provide a means for shortening the lead time of the total process considerably. Modularity can also contribute to a higher level of service and upgrading, as service-sensitive parts can be exchanged quickly. Another advantage is the involvement of different disciplines in creating the assembly process scheme within the working group. Every company discipline and its specific knowledge is involved and used to improve the process and product design. At an early stage of design, everybody agrees on design decisions, which helps prevent costly modifications later. However, using MAS during the design phase requires the discipline and openness of product engineers. Furthermore, time is needed for all participants of the working group.

MAS can also be used as a starting point to develop a new production or assembly flow for a mix of products: the number of (sub)assembly workstations can be assessed. A clearer distinction between the flow and processing of standard and special orders can be made during the design phase. Closed-loop business processes lead to extra demands on the flexibility in and organization of (re)manufacturing processes. There can be very diverse flows of products and components using different routings on a shop floor. For instance, there could be single-piece products or small batches of products coming from customers that need to be disassembled on a disassembly line, components that need to be (re)manufactured, and (new) products that need to be assembled from new and used components and modules.

Finally, as MAS is a process scheme of all the assembly steps to be performed, it is frequently used as a starting point for development of work and test instructions for the operator at every workstation (see Sect. 4 and Fig. 3). 


\section{Product Development: Modular Product Architecture \& Operator-Centred Product Design}

Product design is crucial for the entire product life cycle, such as the production, assembly, use, upgrading and remanufacturing stages. Although the exact numbers are debatable (Ulrich and Pearson 1993), the design literature suggests that, in the average product design stage, $70-80 \%$ of the costs are already defined (e.g., Sheldon et al. 1990). Traditionally, durable goods manufacturing companies focused on designing and producing physical products for their customers and end-users. Today, many of these companies are shifting their focus towards producing value-adding services for their customers. To some extent, these services are independent of the physical products, but in most cases, these products are still at the core of the services as the companies extend their services from traditional spare part delivery and maintenance towards life-cycle services and extended products. The service activities typically focus on maintaining the performance of the physical product (spare parts, repair, preventive maintenance, online monitoring of equipment, IT-support diagnosis, remote support for maintenance) or on informing the user of how to use it (training, consultation, simulation, data services).

In UIW, there has been a focus on the changing role of the product development function in manufacturing companies. The main role of this function in a manufacturing company was to produce a design to fulfil the functional requirements of the products but, since the middle of the 20th century, the focus has moved towards the development of designs suitable for production. In the 1980s, there was a growing demand for easily assembled and manufactured designs. This changed the role of the product development function, which was required to review the designs from a growing number of viewpoints. This development has been called Design for X (Kuo al. 2001). After Design for Assembly and Design for Manufacturing there were, among others, Design for Maintenance, Design for Recycling (Gaustad et al. 2010), Design for Environment (Leonard 1991) and Design for Life-cycle (DFLC) (Ishii et al. 1994).

In the near future, designing products for the circular economy will once again set new requirements for the product development function. Products must be designed in a manner that easily allows upgrades (i.e., adapt to future use, reuse, or remanufacturing) in several closed loops between the customer and manufacturing companies. This requires new methods for identifying (future) user needs and values, module-based development teams instead of department-specific teams, early-stage testing and implementation of upgrades while the product is in use anywhere in the world. An essential part of circular economy-based design is the adaptability of products by introducing product modularity (Krikke et al. 2004) and operator-centred design. Product modularity, an approach based on the decomposition of the product into independent subassemblies (product modules, Ulrich 1995), has proven to have positive effects on multiple dimensions of competitive performance such as product quality, flexibility and lead times (e.g., Jacobs et al. 2007). Using product modularity in a traditional sense, a wide range of final 
products can be configured using flexible methods through intelligent configuration of the product range. Product modularity results in opportunities for parallelizing production processes and thereby considerable lead time reductions for the total manufacturing process can be achieved as long as there is sufficient manpower and space. Modularity also makes it possible to outsource entire sub-modules, such as sheet metal frames, power units, and control cabinets, to specialized suppliers. For circular economy-based design, modularity contributes to a higher level of service and installation, as service-sensitive parts can be exchanged quickly. Furthermore, product modularity supports upgrading the product at the customer site by exchanging modules or reusing used modules in other products within the same product family and thereby adheres to the main principles of the circular economy (i.e., maintain products at their highest utility and value at all times and avoid waste).

In addition to modularity, operator-centred design supports ease of (dis)assembly, maintenance and upgrading and thereby improves operational performance. The Human Factor Design for Assembly (HF-DFA) tool, based on the DFA methodology described by Boothroyd et al. (2001), can be used to evaluate the ease of assembly tasks from an operator perspective (Village et al. 2014) and improve product design. The face validity and simple scoring of the tool facilitates integration into the design process. To support operator-friendly fixture design, the Human Factors Design for Fixture (HF-DFF) guidelines can be applied in the design process (Village et al. 2012). Careful fixture design ensures both product quality and improved human factors. Another methodology that can be used to ensure human-centred product design is Design for Manufacturability (DfM) (Helander and Nagamachi 1992).

\section{New Technologies in Flexible Production Processes: Levels of Automation and Assistive Operator Support}

Once the production process is transparently and flexibly organized, a next step in further improving efficiency can be (partial) automation. Production technology is developing rapidly, and the trend of automation, including the use of robots, collaborative robots and process control systems, has a large impact on manufacturing and on its operators in particular. 'Full automation' however, is often not feasible in production work, specifically in the combination of low volumes, high product mix, and high product complexity. For years, product disassembly has been performed as a primarily manual activity. However, the high demand for manual work together with the labour cost generally make disassembly economically infeasible. To overcome this economic issue, replacing the human labour with full automation has been raised as a potential solution (Vongbunyong and Chen 2015). However, task automation requires a very advanced set of robotic technology and its practical implementation still represents a challenge in terms of robustness, accuracy and 
execution time. Humans are still the most flexible production factor. As smaller batches require higher investments and specialized production systems, especially in assembly, robots and robotic systems will often mainly assist production personnel and remove some routine work. In a semi-structured environment with hybrid production systems, intuitive user interfaces are needed, which could be programmed by operators themselves, to ensure that humans and robot systems are safely collaborating (Robotics 2020: Multi-Annual Roadmap for Robotics in Europe 2015).

In hybrid production systems, human failure is a source of potential error. This requires effective strategies to guarantee human reliability. A strategy to minimize human error is the implementation of automated systems that control the process to a large extent. These may reduce human errors but may also have a large impact on the operator and his or her task. While skilled workers may still be needed, the majority of tasks will become simple and less challenging. Decreased motivation and alertness, potentially jeopardizing human reliability and thereby counteracting potential error-reducing technological measures, are a serious concern. Companies experience these crucial labour issues in production-automation projects, but at the same time, they are 'hard to tackle'. The challenge is finding a good balance between the level of process control and the attractiveness of the work for the operator. Two steps in production automation projects are proven to be crucial (Fasth and Stahre 2010), which are presented in Fig. 4.

- Design of tasks: Task Analysis and Allocation of Task to humans and machines.

- Design of operator support systems in the case of manual activities.

A process map (e.g., MAS) can be used to create an overview of manufacturing process steps followed by a task analysis (e.g., HTA) to define the order of concrete tasks performed by operators and machines. Task allocation is used to allocate tasks to operators or machines. Finally, in the case of manual activities, the need for physical or cognitive support systems is determined.
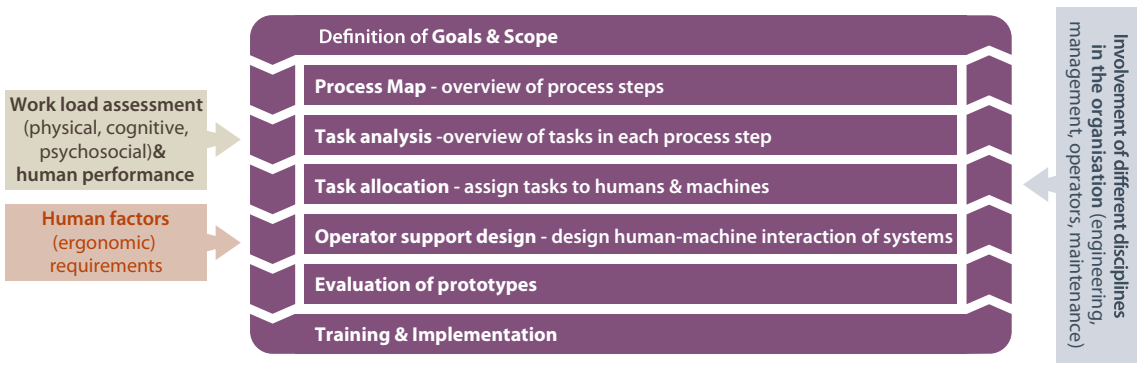

Fig. 4 Schematic overview of the iterative participatory process design approach 


\subsection{Level of Automation}

A first step is to create a well-balanced allocation of activities between humans and robots/machines based on a task analysis. The starting point for this task analysis is the production process analysis, which provides an overview of the process steps to complete an order from beginning to end. Each process step consists of one or more tasks performed by operators and machines. Task analyses can be action oriented approaches (e.g., handling, transportation, picking and placing, replacing tools) or focus on the mental processes as cognitive approaches (e.g., decision making, perception). A common methodology for task analysis is Hierarchical Task Analysis (HTA) described by Stanton (2006). It demonstrates the requirements that tasks necessitate from workers and machines and describes the order of tasks. Task analysis can be used for both current (existing) production processes and new (to be designed) processes.

The result of the task analysis is a starting point for the next step, task allocation between humans and machine. Since Fitts published a set of heuristics on the relative strengths and limitations of humans and machines in 1951 (MABA-MABA, 'men are better at' and 'machines are better at'; Fitts 1951), numerous methodologies have been developed to support task or function allocation between machines/robots and humans. An extensive body of literature describes task allocation models and approaches (e.g., Frohm et al. 2006; Fasth and Stahre 2010; Cummings 2014). In this context, the term Level of Automation (LoA) has been used to describe the relation between humans and technology in terms of task and/or function allocation (Frohm et al. 2006). LoA has been described as an indicator of the allocation of tasks in a manufacturing system and is expressed as an index of physical as well as cognitive tasks. These methodologies focus on balancing performance requirements (zero defects, productivity, costs) and human factors (physical, cognitive load, job satisfaction, motivation, alertness). All of these task allocation models should support the (optimal) division of tasks between robots and operators. The remaining human tasks should not exceed norms, recommendations and guidelines for physical, cognitive, psychosocial load and safety (e.g., ISO 11228-3 2007; ISO 9241 1997; Directive 2002/44/EC). Task allocation is often done once during the (re)design of a manufacturing process. In manufacturing and remanufacturing processes, products and its manufacturing tasks change during the day. There is a need for a more flexible/dynamic task allocation model in which the division between robots and humans can be considered continuously (on the fly), based on human-oriented parameters of workload (physical, cognitive, psychosocial load), safety, flexibility and performance criteria (quality, costs, productivity). 


\subsection{Operator Support Systems}

Workmanship (i.e., craftsmanship) of the workforce, support from tools, support systems and work instructions are crucial ingredients for securing the quality of the manufacturing and assembly process. Especially in low-volume, high-variety and complex tasks, product-specific information and support for operators are required. If there is a (flexible or adaptive) level of automation, the remaining (inspection or manual) tasks of the operator require up to date information for the operator to perform his/her tasks properly. Here, quality refers to minimum failure costs, short lead times, ease of learning, and a high level of reproducibility of the process. In practice, work instructions are often too brief, bear too little relation to the operator's task at hand and are insufficiently systematically updated (Van Rhijn et al. 2014; Aehnelt and Bader 2015). These factors, as well as the unpredictable market, wide variety of products, flexible deployment of employees and diversity in operator characteristics (e.g., experience, backgrounds and languages), emphasize the importance of clear and updated operator assistance. For example, updated work instructions that fulfil the operator needs and feedback systems that provide a clear indication to the operator what went wrong. Especially in closed-loop systems and mixed-model assembly systems (e.g., Zeltzer et al. 2012), operator support and instructions are crucial for effective and efficient processes as the diversity of products coming back from customers is extreme. Aehnelt and Bader (2015) identify five aims of information assistance:

- raising awareness: increase operator awareness of relevant events within the work environment;

- guiding: feedforward and provide instructions;

- monitoring: collect relevant (sensor) data from the actual production setting;

- documenting: document quality issues directly in the system;

- guarding: monitor the actual operator status and prevent overloading.

In addition to these aims, Claeys et al. (2015) recently described a framework to support the development of industrial cognitive support systems. The authors differentiate:

- the information content: what to present. Operators need to have correct information on how to disassemble a product and how to diagnose the level of re-usability.

- the information carrier: how to present information (e.g., Google Glass, computer screens, projection, etc.). Recently, technologies such as Google Glass (Rauh et al. 2015) or gestural recognition software (Niedersteiner et al. 2015), have been used to support operators in assembly work. Augmented Reality technology has been used to assist assembly workers in the aerospace industry (e.g., Servan et al. 2012) and personnel in the field, supporting maintenance and facilitating the upgrade process (Re and Bordegoni 2014).

- in what kind of situation information should be presented: presenting information automatically or upon request depends on the operator needs and task demands. 
Claeys et al. (2015) emphasize the importance of a personalized configuration, i.e., modifying instructions and feedback depending on the current state of the operator and the task at hand. Work instructions should be set out in a modular manner and applied in accordance with the degree of experience of the employees. In both manual and semi-automated or hybrid processes, operator guidance should be experienced as added value and should therefore not dictate either posture or work pace to avoid operator annoyance. The interaction should be natural and effortless. High system reliability is needed to avoid operator annoyance and mistakes (e.g., error messages should not occur if a correct action has been performed by the operator). Operator support guidelines for transferring information using text, images or signals must be used so that the information is more appropriately tailored to the operator and task at hand.

\section{Conclusions}

In the near future, short product development lead times, proven sustainability, flexibility, and upgrades will become crucial elements to guarantee competitive business in the manufacturing industry. Upgrading high-investment products driven by rapidly changing customer demands requires highly modular product design, flexible production processes (for new, refurbished and remanufactured products) including (semi) automated and manual workstations and a flexible, motivated and skilled workforce. To face these challenges, several methods and tools for both product, process and task design are described in scientific and grey literature. Several of these methods are described in this chapter. However, many manufacturing companies, especially smalland medium-sized enterprises, do not use these tools and methods. Possible reasons for this are that the methods are not well known or that there is a lack of experience using the tools in a correct manner. Furthermore, the practical application of scientific methodologies is difficult for engineers, as the methodologies do not use the language of their users (e.g., engineers) or are not part of their standardized working procedures, for instance, see Village et al. (2012) regarding ergonomics.

In addition to barriers for efficient tool use in companies, further development of methodologies should be closely connected to future company needs. For instance, most of the current methods are suitable and developed for designing products and processes based on the more traditional linear economy. The circular economy emphasizes the reusability of products and raw materials as a starting point and minimizing waste in the entire industrial and ecological system. Designing adaptable and upgradable products and flexible (re)manufacturing processes are crucial aspects in realizing a circular economy-based business. These aspects should be 
considered and integrated in the next generation of methods for product and process design.

Finally, communities of practice (see Houghton, Chapter "Fostering a Community of Practice for Industrial Processes" this book) could serve as a dedicated platform to share state-of-the-art methodologies, tools and checklists and documentation of company best practices so that practical cases and tools could be made available to SME companies.

Acknowledgements The authors would like to thank Michiel de Looze and Karin Verploegen for their useful comments on earlier versions of this chapter.

\section{References}

Aberdeen Group (2014). Bridging the gap between product development and operations. http://www. aberdeen.com/research/9340/rr-manufacturing-product-development/content.aspx\#sthash.

K8rq0kXI.dpf

Aehnelt, M., \& Bader, S. (2015). Information assistance for smart assembly stations. In Proceedings of the 7th International Conference on Agents and Artificial Intelligence (pp. 143-150).

APPSRG (2014). Remanufacturing: Towards a resource efficient economy. All Party Parliamentary Sustainable Resource Group.

Bastein, T., Roelofs, E., Rietveld, E., \& Hoogendoorn, A. (2013). Kansen voor de circulaire economie in Nederland. Delft, The Netherlands: TNO.

Bloom, D. E., Canning, D., \& Lubet, A. (2015). Global population aging: Facts, challenges, solutions \& perspectives. Daedalus, 144(2), 80-92.

Boothroyd, G., Dewhurst, P., \& Knight, W. A. (2001). What is design for manufacture and assembly? Product design for manufacture and assembly (pp. 1-44). Boca Raton, FL: CRC Press, Taylor and Francis.

Bouckenooghe, D., \& Devos, G. (2007). The role of process, context and individual characteristics in explaining readiness to change: A multilevel analyses. Vlerick Leuven Gent Working Paper Series 2007/12.

Challenger, R., Clegg, C. W., \& Shepherd, C. (2013). Function allocation in complex systems: Reframing an old problem. Ergonomics, 56(7), 1051-1069.

Claeys, A., Hoedt, S., Soete, N., Van Landeghem, H., \& Cottyn, J. (2015). Framework for evaluating cognitive support in mixed model assembly systems. IFAC-PapersOnLine, 48(3), 924-929.

Cummings, M. M. (2014). Man versus machine or man + machine? IEEE Intelligent Systems, 29 (5), 62-69.

DIRECTIVE 2002/44/EC of 25 June 2002 on the minimum health and safety requirements regarding the exposure of workers to the risks arising from physical agents (vibration) (sixteenth individual Directive within the meaning of Article 16(1) of Directive 89/391/EEC).

Department for Business, Innovations and Skills (2012). Low carbon environmental goods and services.

Ellen MacArthur Foundation (2013). Towards the circular economy. In: Economic and Business Rationale for an Accelerated Transition, Vol. 1. Ellen MacArthur Foundation available from: www.ellenmacarthurfoundation.org 
European Foundation for the Improvement of Living and Working Conditions (1999). Communique, July/August, Vol. 2. EFILWC, Dublin.

Fasth, A., \& Stahre, J. (2010). Concept model towards optimising Levels of Automation (LoA) in assembly systems. In Proceedings of the 3rd CIRP Conference on Assembly Technologies and Systems, Trondheim, Norway.

Fitts, P. M. (1951). Human engineering for an effective air navigation and traffic control system. Tech. Report, Nat'l Research Council.

Frohm, J., Granell, V., Winroth, M., \& Stahre, J. (2006). The industry's view on automation in manufacturing. In F. Mayer, \& J. Stahre (Eds.), Proceedings of the 9th Symposium IFAC on Automated Systems Based on Human Skills and Knowledge.

Gaustad, G., Olivetti, E., \& Kirchain, R. (2010). Design for recycling. Journal of Industrial Ecology, 14(2), 286-308.

Genaidy, A., \& Karwowski, W. (2007). A roadmap for a methodology to assess, improve and sustain intra- and inter-enterprise system performance with respect to technology-product life cycle in small and medium manufacturers. Human Factors and Ergonomics in Manufacturing, 18(1), 70-84.

Ginn, D. M., Jones, D. V., Rahnejat, H., \& Zairi, M. (1998). The "qfd/fmea interface". European Journal of Innovation Management, 1(1), 7-20.

Helander, M., \& Nagamachi, M. (1992). Design for manufacturability: A systems approach to concurrent engineering and ergonomics Taylor \& Francis.

Hirschheim, R. (1989). User participation in practice: Experiences with participative system design. In K. Knight (Ed.), Participation in Systems Development (pp. 194-204). Columbia GP Publishing.

Ishii, K., Eubanks, C. F., \& Di Marco, P. (1994). Design for product retirement and material life-cycle. Materials and Design, 15(4), 225-233.

International Standard Organisation ISO 11228-3. Ergonomics-manual handling: Part 3: Handling of low loads at high frequency, 2007.

EN ISO 9241-1:1997 "Ergonomic requirements for office work with visual display terminals (VDTs)_Part 1: General introduction (ISO 9241-1:1997/Amd. 1:2001)" and its amendment A1:2001.

Jacobs, M., Vickery, S. K., \& Droge, C. (2007). The effects of product modularity on competitive performance: Do integration strategies mediate the relationship? International Journal of Operations \& Production Management, 27(10), 1046-1068.

Krikke, H., le Blanc, I., \& van de Velde, S. (2004). Product modularity and the design of closed-loop supply chains. California Management Review, 46(2), 23-39.

Kuo, T. C., Huang, S. H., \& Zhang, H. C. (2001). Design for manufacture and design for ' $\mathrm{X}$ ': Concepts, applications, and perspectives. Computers \& Industrial Engineering, 41(3), 241-260.

Leonard, L. (1991). Design for environment. In Plastics Design Forum: 25-32.

Lines, R. (2004). Influence of participation in strategic change: Resistance, organizational commitment and change goal achievement. Journal of Change Management, 4(3), 193-215.

McKinsey (2011). Resource revolution: Meeting the world's energy, materials, food, and water needs. McKinsey Global Institute; McKinsey and Company Sustainability, Resource Productivity Practice. Available from: http://www.mckinsey.com/mgi

Muller, M. J., \& Kuhn, S. (1993). Participatory design. Communications of the ACM, 36, 24-28.

Niedersteiner, S., Pohlt, C., \& Schlegl, T. (2015). Smart workbench: A multimodal and bidirectional assistance system for industrial application. In Industrial Electronics Society (pp. 2938-2943).

Quan, W., \& Jianmin, H. (2006). A study on collaborative mechanism for product design in distributed concurrent engineering. IEEE 7th International Conference on Digital Object Identifier (pp. 1-5). 
Rauh, S., Zsebedits, D., Tamplon, E., Bolch, S., \& Meixner, G. (2015). Using Google Glass for mobile maintenance and calibration tasks in the AUDI A8 production line. In Emerging Technologies \& Factory Automation (pp. 1-4).

Re, G. M., \& Bordegoni, M. (2014). An augmented reality framework for supporting and monitoring operators during maintenance tasks. In R. Shumaker \& S. Lackey (Eds.), Virtual, augmented and mixed reality applications of virtual and augmented reality (pp. 443-454). Berlin: Springer.

van Rhijn, J. W., de Looze, M. P., Tuinzaad, G. H., Groenesteijn, L., de Groot, M. P., \& Vink, P. (2005). Changing from batch to flow assembly in the production of emergency lighting devices. International Journal of Production Research, 43, 3687-3701.

Rhijn van, J.W., Tuinzaad, B., Bosch, T., \& Vos, F. (2014). Increasing productivity and flexibility in manufacturing. TNO Hoofddorp.

Robotics 2020: Multi-annual roadmap for Robotics in Europe (2015). http://sparc-robotics.eu/wpcontent/uploads/2014/05/H2020-Robotics-Multi-Annual-Roadmap-ICT-2016.pdf

Rother, M., \& Shook, J. (2003). Learning to see: Value stream mapping to add value and eliminate muda. Lean Enterprise Institute.

Pot, F., \& Rhijn van, J.W. (2012). Slimmer Werken in het MKB van de maakindustrie. http:// www.industriebeleid.nl/documenten/Slimmer\%20werken\%20in\%20het\%20MKB\%20van\% 20de\%20maakindustrie.pdf

Servan, J., Mas, F., \& Menendez, J.L. et al (2012). Using augmented reality in AIRBUS A400M shop floor assembly work instructions. In The 4th Manufacturing Engineering Society International Conference, Cadiz (pp. 633-640).

Shalley, C. E., Zhou, J., \& Oldham, G. R. (2004). The effects of personal and contextual characteristics on creativity. Journal of Management, 30, 933-958.

Sheldon, D. F., Perks, R., Jackson, M., Miles, B. L., \& Holland, J. (1990). Designing for whole life costs at the concept stage. Journal of Engineering Design, 1, 131-145.

Smart industry, Dutch industry fit for the future (2014). http://www.smartindustry.nl/wp-content/ uploads/2014/07/Opmaak-Smart-Industry.pdf

Stamatis, D.H. (2003). Failure mode and effect analysis: FMEA from theory to execution. ASQ Quality Press.

Stanton, N. A. (2006). Hierarchical task analysis: Developments, applications, and extensions. Applied Ergonomics, 37(1), 55-79.

Suri, R. (1998). Quick response manufacturing: A companywide approach to reducing lead times. Productivity Press.

Ulrich, K. T. (1995). The role of product architecture in the manufacturing firm. Research Policy, 24(3), 419-440.

Ulrich, K.T., \& Pearson, S.A. (1993). Does product design really determine $80 \%$ of manufacturing cost? Working paper. Massachusetts: Sloan School of Management Cambridge.

Village, J., Greig, M., Zolfaghari, S., Salustri, F., \& Neumann, W. P. (2014). Adapting engineering design tools to include human factors. IIE Transactions on Occupational Ergonomics and Human Factors, 2(1), 1-14.

Village, J., Annett, T., Greig, M., \& Neumann, W.P. (2012). Ergonomic design-for-fixture guidelines and process of implementation. A case study. In Association of Canadian Ergonomists Annual Conference, Halifax, Nova Scotia. http://digitalcommons.ryerson.ca/ie/27/

Vink, P., Imada, A. S., \& Zink, K. J. (2008). Defining stakeholder involvement in participatory design processes. Applied Ergonomics, 39(4), 519-526. 
Vongbunyong, S., \& Chen, W.H. (2015). Disassembly automation: Automated systems with cognitive abilities. Springer.

Zeltzer, L., Limere, V., Aghezzaf, E.H., \& Van Landeghem, H. (2012). Measuring the objective complexity of assembly workstations. In ICCGI 2012, The Seventh International Multi-Conference on Computing in the Global Information Technology (pp. 341-346).

Open Access This chapter is licensed under the terms of the Creative Commons Attribution-NonCommercial 4.0 International License (http://creativecommons.org/licenses/by-nc/ 4.0/), which permits any noncommercial use, sharing, adaptation, distribution and reproduction in any medium or format, as long as you give appropriate credit to the original author(s) and the source, provide a link to the Creative Commons license and indicate if changes were made.

The images or other third party material in this chapter are included in the chapter's Creative Commons license, unless indicated otherwise in a credit line to the material. If material is not included in the chapter's Creative Commons license and your intended use is not permitted by statutory regulation or exceeds the permitted use, you will need to obtain permission directly from the copyright holder.

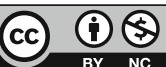

